\title{
Experiências na formação inicial: primeiras interações com a sala de aula
}

\author{
Experience in teaching training: first classroom interactions
}

\author{
Giovana Laís Eckert (eckert.giovana@gmail.com)
}

Universidade Federal da Fronteira Sul - UFFS

Resumo: As experiências em sala de aula são, em grande parte, responsáveis pela constituição da Identidade Profissional do Professor, que, em complemento e auxílio das teorias tornam cada vez mais presentes a realidade escolar e docente dos professores em formação inicial. Esse relato de experiência visa proporcionar uma reflexão acerca da formação inicial, importância do diário de bordo, autoscopia, planejamento e, principalmente, das experiências em sala de aula na constituição do Professor de Ciências e Biologia. A partir de duas aulas sobre de Desastre Ambiental do Rio Doce, orientadas e planejadas como Projeto Interdisciplinar na disciplina de Práticas de Ensino III, curso de Licenciatura em Ciências Biológicas, na Universidade Federal da Fronteira Sul (UFFS) - Campus Cerro Largo, produzidas em uma turma de primeiro ano em uma cidade na região das Missões no Rio Grande do Sul, que configuraram o primeiro contato dos licenciandos com a sala de aula na função de professores, tornando explicitas teorias e a dificuldade, complexidade e papel indispensável do Professor.

Palavras-chave: Formação Inicial; Autoscopia; Diário de Bordo.

Abstract: Classroom experiences are, most of the time, responsible for the construction of Teacher's Professional Identity, which, complementing the theories and using them and as an aid, become gradually more present in the scholar and teaching realities of teachers in initial training. This experience report aims to reflect on initial training and the importance of journals, autoscopy, planning and, mainly, classroom experiences in the construction of the Biology and Science Teacher. The research investigated two classes about the environmental disaster of Rio Doce, which were advised and planned as an Interdisciplinary Project in the subject Práticas de Ensino (Teaching Practices) III, from the graduation course of Biological Sciences, in the Universidade da Fronteira Sul (UFFS) - Campus Cerro Largo. They were produced in a first-year of high school class in a city in the Missões region, in the state of Rio Grande do Sul. Such classes constituted the first contact of the undergraduate students with the classroom as teachers, making explicit the theories and difficulty, complexity and the essential role of the teacher.

Keywords: Initial training; autoscopy; jornal.

\section{CONTEXTUALIZAÇÃo}




\section{Vol. 2, n. 3 - Edição Especial: Ciclos Formativos em Ensino de Ciências.}

A formação inicial de professores deve permear todas as discussões que tratam de educação, uma vez que, de acordo com Nóvoa (1954, p. 9) "Não há ensino de qualidade, nem reforma educativa, nem inovação pedagógica sem uma adequada formação de professores".

Assim, a formação de professores próxima à realidade escolar configura a mudança necessária em sala de aula, traçando, dessa forma, os novos rumos da educação brasileira, uma vez que, de acordo com Pimenta (1996)

\footnotetext{
os cursos de formação têm demonstrado que, ao desenvolverem um currículo formal com conteúdos e atividades de estágio distanciados da realidade das escolas, pouco tem contribuído para gestar uma nova identidade do profissional docente. (PIMENTA, 1996, p. 72)
}

As aulas nesse relato refletidas faziam parte da proposta do Projeto Interdisciplinar da terceira fase do curso de Ciências Biológicas da Universidade Federal da Fronteira Sul (UFFS), campus Cerro Largo, orientadas pelo professor do Componente Curricular (CCR) de Práticas de Ensino III: metodologia e didática do ensino de ciência e biologia. As aulas foram ministradas em uma turma do primeiro ano do Ensino Médio, em uma cidade da região das Missões no Rio Grande do Sul. O planejamento foi de 4 horas/aula, destas, apenas duas foram efetivadas em um grupo de cinco Professores em formação inicial, todos alunos da terceira fase do curso de Ciências Biológicas e participantes do CCR. O planejamento foi realizado pensando em um viés investigativo, buscando tornar a aula interativa e de fácil assimilação para os alunos.

O tema central da aula foi o Desastre Ambiental do Rio Doce, que ocorreu em 5 de novembro de 2015, data do rompimento da Barragem do Fundão, no distrito de Bento Rodrigues, município de Mariana-MG, de propriedade da mineradora Samarco, uma união entre as duas maiores mineradoras do Mundo (Vale S.A. e a anglo-australiana BHP Billiton). O impacto do rompimento da barragem não se restringiu às áreas próximas do barramento, seus efeitos negativos se estenderam pelos $663 \mathrm{~km}$ dos rios Gualaxo do Norte, Carmo e Doce, até penetrar nas águas oceânicas do estado do Espírito Santo. Além disso, o desastre implicou na destruição das povoações de Bento Rodrigues, com a morte de 19 pessoas, atingiu também os distritos de Paracatu de Baixo e Gesteira, a cidade de 


\section{Vol. 2, n. 3 - Edição Especial: Ciclos Formativos em Ensino de Ciências.}

Barra Longa e mais cinco povoados no distrito de Camargo, em Mariana, além da barragem de Candonga. Mais de 1.200 pessoas ficaram desabrigadas, pelo menos 1.469 hectares de terras ficaram destruídas, além de áreas de preservação permanente (APP) e unidades de conservação, incluindo o Parque Estadual do Rio Doce (ESPINDOLA et al, 2016).

Este foi o maior desastra ambiental brasileiro, ao romper, a barragem liberou um volume estimado em 34 milhões de $\mathrm{m}^{3}$ de rejeitos de mineração, água e materiais utilizados em sua construção, além de carregar consigo os restos de atividades humanas e ambientais que foram carregados junto com a lama. Os impactos foram amplos e diversos, tanto para humanos como para a biodiversidade (ESPINDOLA et al, 2016)

Na questão ambiental, Espindola et al, aponta que:

a Bacia do Rio Doce está inserida em sua quase totalidade no bioma Mata
Atlântica $(98 \%)$, tento no extremo oeste uma pequena porção no bioma
Cerrado $(2 \%)$. [...] os remanescentes desta porção do bioma Mata Atlântica são
importantes pela biodiversidade que preservam e, especialmente, o pelo
intenso endemismo. Toda floresta presta serviços ecológicos imprescindíveis
para a vida no seu interior e os seres humanos, tais como a produção de
biomassa, produção de água, regulação do clima, armazenamento de carbono,
produção de alimentos e habitat para animais, sem contar, a importância da
própria paisagem florestal. (ESPINDOLA et al, 2016, p. 91 )

As aulas ministradas configuraram o primeiro contato dos acadêmicos com a sala de aula no papel de professores, como entes responsáveis pelo desenvolvimento do entendimento de seus alunos. Essa experiência foi, sem dúvidas, engrandecedora no sentido formativo, uma vez que a graduação deve proporcionar o contato real entre os acadêmicos e as vivências escolares.

Os meios utilizados para a reflexão foram o diário de bordo, que, de acordo com Porlán e Martin (1997), as escritas permite refletir o ponto de vista do professor sobre os processos mais significativos da dinâmica de ensino. Além da autoscopia, que consiste na gravação da prática docente e posterior reflexão sobre ela, que foi realizada em um "ensaio da aula", antes de sua execução propriamente dita, essa prática "permite o desenvolvimento da auto-observação e da autocrítica, sendo uma oportunidade de 


\section{Vol. 2, n. 3 - Edição Especial: Ciclos Formativos em Ensino de Ciências.}

diagnosticar comportamentos pedagógicos para melhorar, buscando aperfeiçoar a ação de cada um" (ARRIGO e LORENCINI, 2015, p. 3)

O presente relato pretende refletir acerca da importância do contato com a sala de aula desde a formação inicial de professores de Ciências e Biologia, além da importância do diário formativo e da autoscopia na constituição do Ser Professor, a partir da primeira experiência em sala de aula, com a produção de duas aulas sobre o Desastre Ambiental do Rio Doce.

\section{DESCRIÇÃO DAS ATIVIDADES}

O planejamento das aulas foi realizado de forma conjunta, entre cinco integrantes no componente curricular de Prática de Ensino III: metodologia e didática do ensino de ciência e biologia, na terceira fase do curso de Ciências Biológicas da Universidade Federal da Fronteira Sul (UFFS), campus Cerro Largo. Como consequência da redução do número de aulas, de quatro do planejamento para duas em sala de aula, foram produzidas a primeira e a segunda aula.

Concluído o planejamento, seguimos para um "ensaio" do que seria a aula, e, como tarefa inclusa na avaliação do professor ministrante da Prática de Ensino III, realizamos a autoscopia bifásica, que, de acordo com Arrigo e Lorencini (2015), é dividida em fase de desenvolvimento, que caracteriza a ação propriamente dita, onde o professor em formação ministra a sua aula, a qual é assistida pelos colegas e pelo professor formador e gravada em forma de vídeo. A segunda fase, de visionamento, o professor em formação assiste o registro de sua aula "confrontando com a sua própria prática, como sendo uma oportunidade de rever os seus comportamentos e registrar os aspectos mais e menos positivos" (ARRIGO e LORENCINI, p. 3, 2015). Refletindo dessa forma sobre nossa prática e tornando-nos mais conscientes de nosso papel como Professor.

A primeira aula foi planejada a partir da metodologia de aula expositiva dialogada, iniciando com uma abordagem oral dos conhecimentos prévios dos alunos sobre o tema, com as ideias anotadas no quadro, seguida da utilização de slides para explicar os aspectos 


\section{Vol. 2, n. 3 - Edição Especial: Ciclos Formativos em Ensino de Ciências.}

gerais do desastre -onde ocorreu, o que aconteceu, quem eram os responsáveis, por que aconteceu, o que é um desastre ambiental-, ao final da aula, os alunos foram indagados a propor possíveis consequências do Desastre do Rio Doce, utilizando para isso, a metodologia do brainstorming ("tempestade de ideias"). Essa metodologia, de acordo com Marques et al (2017) permite desenvolver a criatividade dos alunos e a produção de diversas ideias em pouco tempo, ela inicia-se com um tema (que no caso da aula era sobre as consequências do Desastre Ambiental do Rio Doce), onde os alunos falam sobre ele enquanto o professor registra no quadro as ideias. Em seguida, as ideias são agrupadas e ou eliminadas, levando a construção de conceitos.

$\mathrm{Na}$ segunda aula, as ideias da anterior foram retomadas as opiniões sobre as consequências tidas na última aula, mais uma vez, os slides foram utilizados como forma de explanação dos seguintes pontos: Perda de biodiversidades (espécies endêmicas e exóticas, tanto animais quanto vegetais), bioacumulação e concentração dos metais pesados, consequências sociais e econômicas para a população residente. Ao final da aula, ocorreu a discussão dos seguintes pontos: "Quais as medidas que podem ser tomadas para evitar que desastres semelhantes aconteçam novamente?", "A área atingida voltará às condições anteriores ao desastre? Como poderá ser limpa a área contaminada? Proponha soluções criativas para esse processo", "O que aconteceria se um desastre dessa magnitude ocorresse na sua cidade?”, “Quais eram as ilegalidades que existiam?”, “Qual a atual situação das famílias atingidas? como remuneração, indenizações, moradia e emprego", além de ambos os grupos buscar possíveis culpados para o desastre.

No planejamento original com quatro aulas, esses questionamentos seriam apresentados em forma de cartazes na terceira aula, enquanto na quarta, seria realizado um júri simulado afim de que apontassem os possíveis culpados do desastre.

A turma do primeiro ano do Ensino Médio era composta por cerca de vinte alunos, a escola possuía uma estrutura boa, apesar de simples e com prédio antigo e pequeno, a sala era equipada com Datashow e caixas de som, quadro branco, classes inteiras, armários e cartazes espalhados pelas paredes. Era visível na sala as diferenças sociais 


\section{Vol. 2, n. 3 - Edição Especial: Ciclos Formativos em Ensino de Ciências.}

entre os alunos, além de diferenças nas formas de interação, deixando a impressão da complexidade de dar aula e a particularidade de cada aluno.

As duas aulas foram em dias diferentes, com 50 minutos cada. Em um primeiro momento, os alunos sentiram-se acanhados e pouco participaram da discussão inicial, além disso, tiveram poucas dúvidas. Porém, o brainstorming os tornou participativos, culminando em uma tabela contendo as consequências divididas em Ambientais, Sociais e Econômicas, os alunos puderam perceber que algumas consequências-como a contaminação da água- perpassava as três esferas, gerando uma discussão sobre a complexidade do tema e suas consequências irreparáveis.

Na segunda aula, os alunos participaram ativamente, inclusive, as discussões sobre as questões ficaram incompletas, por falta de tempo ao final da aula. Após, realizamos a reflexão no diário de bordo, que se constitui em um guia para a reflexão sobre a prática, estabelecendo, assim, conexões significativas entre o conhecimento prático e o conhecimento disciplinar (PORLÁN e MARTIN, 1997)

Creio que aulas foram satisfatórias, os alunos compreenderam a importância do tema e, nós, professores, saímos da sala de aula com a certeza da escolha certa e reafirmando nossa posição como entes mediadores, mantenedores e insubstituíveis no Ensino. Outrossim, conceitos antes tão abstratos das teorias de ensino tornaram-se claros, como o currículo, currículo oculto, planejamento e prática docente, além de destacar a importância das escritas reflexivas no diário de bordo e da autoscopia, que serviram como um reencontro com os momentos em sala de aula e uma constante reflexão e ressignificação daquelas aulas.

O relato aqui escrito traz a interação entre a prática desenvolvida com o processo de escrita e reflexão no diário de bordo levando a uma autoscopia da própria constituição do Ser Professor.

\section{DISCUSSÃO DO RELATO}




\section{Vol. 2, n. 3 - Edição Especial: Ciclos Formativos em Ensino de Ciências.}

Em concordância com Leite e Radetzke (2018), uma das etapas mais importantes dos cursos de formação de professores são as vivências no dia-a-dia da escola, uma vez que estas possibilitam aos futuros professores a construção de novos olhares e perspectivas com a profissão e, assim, promovem o início da construção da identidade profissional. Portanto, as experiências em sala de aula são pontos importantes na formação inicial, uma vez que em um passado todo o professor em formação já foi aluno e carrega consigo um conjunto de crenças e de ideias sobre o ensino e sobre o que significa ser professor que foram interiorizadas ao longo da trajetória escolar. Ao contrário da formação de outros futuros profissionais, como professores, já conhecemos o contexto no qual iremos exercer a nossa atividade: as escolas e as salas de aula (FLORES, 2010).

Assim, é essencial que ocorra o desenvolvimento de compreensões profundas acerca do ensino e da aprendizagem investigando a própria prática (FLORES, 2010) em sala de aula, para que ocorra a redescoberta do espaço escolar, contudo agora, no papel de Professor. De acordo com Nóvoa (1954, p. 24) "a formação deve estimular uma perspectiva crítico-reflexiva, que forneça aos professores os meios de um pensamento autônomo [...] com vista à construção de uma identidade, que é também uma identidade profissional". Dessa forma, a partir das escritas no diário de bordo e da autoscopia foi possível refletir sobre a prática e torna-la parte do processo da constituição da identidade de professor.

O Diário de Bordo, possibilita a organização do pensamento, a retomada, a sistematização e a reflexão das experiências vivenciadas no contexto escolar. Assim, o descrevermos a nossa prática nos reaproximamos das vivências nelas contidas, além de ser possível a identificação de dificuldades, anseios, problemas e soluções. (DIAS et al, 2013).

Outro processo utilizado como reflexão foi a autoscopia bifásica que possui os seguintes objetivos:

realizar os processos de reflexão sobre a ação e sobre a reflexão-na-ação na formação reflexiva de estudantes (...), no sentido de promover reflexões para as ações futuras, o que implica um movimento de transformação da prática 


\section{Vol. 2, n. 3 - Edição Especial: Ciclos Formativos em Ensino de Ciências.}

educativa dos licenciandos, futuros professores. (ARRIGO e LORENCINI, 2015 , p. 2)

A autoscopia, em nossa prática, realizou-se de forma escrita, as palavras:

produzem sentido, criam realidades e, às vezes, funcionam como potentes mecanismos de subjetivação. (...) As palavras determinam nosso pensamento porque não pensamos com pensamentos, mas com palavras, não pensamos a partir de uma suposta genialidade ou inteligência, mas a partir de nossas palavras (Larrosa, 2002, p. 21)

Assim, configurou uma fase preparatória da aula ministrada, identificando vícios de linguagem, postura e forma de ensinar, também, foi importante na reformulação da prática. No diário de bordo, ao falarem da autoscopia, identificamos aspectos importantes da nossa prática, como carências na dicção, relacionadas ao conteúdo e posturais, como no trecho em que durante a fala "era um ciclo entre mexer as mãos e na roupa", também percebemos como nos espelhamos em nossos próprios professores, como no trecho "percebi aspectos que observava em meus professores e que carreguei junto a mim na minha constituição profissional, uma vez que absorvemos aos poucos o que aprendemos de nossos professores formadores".

A experiência aqui refletida foi de grande importância na formação docente por ser a primeira relação entre a teoria vista na Universidade e a prática em uma sala de aula. Durante o planejamento e ao decorrer da aula, tornaram-se explicitas algumas das dificuldades debatidas em sala de aula, como a dificuldade de criar uma aula sem conhecer a turma, não tendo controle sobre o tempo e a manifestação do currículo oculto.

Segundo Flores (2010, p. 184) é importante

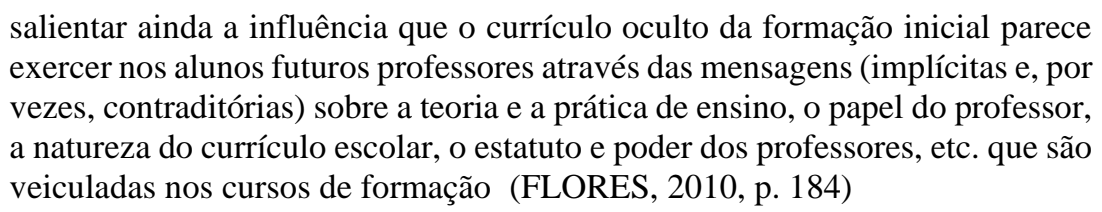

No Diário de Bordo, essas percepções tornaram-se reflexões quando falamos que "Sei que não são os reais objetivos formar para quem apenas quer ser formado, mas a escola e turma forma sensacionais, o sonho de qualquer professor". As impressões do 


\section{Vol. 2, n. 3 - Edição Especial: Ciclos Formativos em Ensino de Ciências.}

começo da aula, escritas em um tom de receio, como no trecho "Confesso que estava nervoso e com medo de como a turma reagiria a nossa aula", transformaram-se em "estou ansioso para retornar lá e continuar a aula", ao final da primeira aula.

A compreensão da intensidade e complexidade do Ser Professor recaíram sobre o grupo: estávamos sozinhos, frente a vinte alunos, empolgados -alguns, talvez entediadose sob nossa inteira responsabilidade pedagógica, naquele momento, tornávamos agentes da metamorfose que almejávamos, e, por menor que fosse nossa interação, acrescentamos algo em sua formação e, nossos alunos, a nossa. Esse momento de interação, no diário de bordo tornou-se expresso em trechos como: "foi um processo muito prazeroso e harmônico, senti-me como professor de fato, como se estivesse com uma afinidade de tempos com a turma" e "estar na sala de aula na posição de professora foi incrivel (...) me tornei Professora naquele momento, reafirmando os objetivos de estar nesse curso"

Sobre o assunto, conseguimos atingir nosso objetivo: tornar perceptível o quão prejudicial o Desastre Ambiental do Rio Doce foi às esferas sociais, econômicas e principalmente ambientais, contribuindo na constituição dos nossos alunos como cidadãos críticos e conscientes das necessidades ambientais que nos constituem seres humanos.

Deixamos a escola após o segundo dia com a sensação de escolha certa e reafirmação do nosso papel, tanto acadêmico, quanto formador de novas opiniões, dividindo o espaço entre aprender e ensinar, na dinâmica de ser professor.

\section{CONCLUSÕES}

As aulas ministradas representaram uma boa experiência formativa, que a partir das reflexões tornaram-se experiência em concordância com Larrosa (2002, p. 20) "A experiência é o que nos passa, o que nos acontece, o que nos toca. Não o que se passa, não o que acontece, ou o que toca", tornando ainda explicitas teorias que vimos nas Universidade.

Contudo, é perceptível que a formação inicial distanciada da prática é, em grande parte, afastada dos objetivos acadêmicos dos cursos de licenciatura. Uma vez que é 


\section{Vol. 2, n. 3 - Edição Especial: Ciclos Formativos em Ensino de Ciências.}

preciso que os futuros profissionais do ensino saibam romper continuamente com os limites do já dito, do já conhecido, respondendo com criatividade e eficácia aos desafios da prática (ARRIGO E LORENCINI, 2015)

Portanto, o contato com a sala de aula é de extrema importância na constituição do professor em formação inicial. Compreender as dificuldades, aprender a ensinar e a dinâmica de uma escola são fatores importantes e indispensáveis que não são supridos apenas com a teoria.

\section{REFERÊNCIAS}

ARRIGO, Viviane; LORENCINI, Álvaro. Formação de professores de Ciências 1 A autoscopia bifásica como estratégia de intervenção reflexiva nas atividades de microensino para formação de estudantes de Química. In: X Encontro Nacional de Pesquisa em Educação em Ciências - X Enpec, Águas de Lindóia. 2015. p. 1 - 8. DIAS, Viviane Borges et al. O Diário de Bordo como ferramenta de reflexão durante o Estágio Curricular Supervisionado do curso de Ciências Biológicas da Universidade Estadual de Santa Cruz - Bahia. In: Encontro Nacional de Pesquisa em Educação em Ciências - Enpec, 9, 2013, Águas de Lindóia. 2013. p. 1 - 17.

ESPINDOLA, Haruf Salmen et al. Desastre da Samarco no Brasil: desafios para a conservação da biodiversidade. Fronteiras: Journal of Social, Technological and Environmental Science, [s.1.], v. 5, n. 3, p.72-100, 19 dez. 2016. Fronteiras: Journal of Social, Technological and Environmental Science. Pag. 72-100.

FLORES, Maria Assunção. Algumas reflexões em torno da formação inicial de professores. Educação, 2010, 33.

LARROSA, Jorge Bondía. Notas sobre a experiência e o saber de experiência. Revista Brasileira de Educação, n. 19, p.2-0-28, Jan/Fev/Mar/Abr 2002.

LEITE, Fabiane de Andrade; RADETZKE, Franciele Siqueira. Prepara, Chegou a hora de ser Professora! Horizontes - Revista de Educação, Dourados, Ms, v. 5, n. 9, p.146158, Jan-Jun, 2017. 
Revista Insignare Scientia

Vol. 2, n. 3 - Edição Especial: Ciclos Formativos em Ensino de Ciências.

MARQUES, Marilaine de Castro Pereira et al. Contribuições da Técnica de Ensino

Brainstorming: Uma Experiência com Estudantes de uma Escola Estadual de Alta

Floresta-MT. Id On Line Multidisciplinary And Psycology Journal, v. 11, n. 37, p.318-328, 2017

NÓVOA, António (Org.). Os Professores e Sua Formação. Lisboa: Publicações Dom Quixote Instituto de Inovação Educacional, 1995. 158 p.

PIMENTA, Selma Garrida. Formação de professores- Saberes da docência e Identidade do Professor. Revista Faculdade da Educação. São Paulo, v. 22, n. 2, pag. 72-74.

PORLÁN, Rafael; MARTÍN, José. El diario del profesor. Sevilla: Díada Editora, 1997. 